\section{Protective role of Plumbago zeylanica extract against the toxic effects of ethinylestradiol in the third instar larvae of transgenic Drosophila melanogaster (hsp70-lacZ) Bg9 and cultured human peripheral blood lymphocytes}

\author{
Yasir Hasan Siddique, ${ }^{1}$ Gulshan Ara, ${ }^{2}$ \\ Mohammad Faisal,3 Mohammad Afzal2 \\ 1Drosophila Transgenics Laboratory, \\ Section of Genetics, Department of \\ Zoology, Aligarh Muslim University, \\ Aligarh, India; ${ }^{2}$ Human Genetics and \\ Toxicology Laboratory, Section of \\ Genetics, Department of Zoology, Aligarh \\ Muslim University, Aligarh, India; ${ }^{3}$ Forest \\ Entomology Division, Forest Research \\ Institute, Dehradun, UK
}

\begin{abstract}
In the present study the effects of Plumbago zeylanica extract were studied against the toxic effects induced by $10 \mu \mathrm{M}$ of ethinylestradiol in cultured human peripheral blood lymphocytes using chromosomal aberrations as a parameter and in the third instar larvae of transgenic Drosophila melanogaster (hsp70lacZ) $B^{9}$ (by 0.50 and $1.0 \mu \mathrm{l} / \mathrm{mL}$ of ethinylestradiol) using hsp70 expression as a parameter. The selected doses of $P$. zeylanica extract i.e. $1.075 \times 10^{-4}, \quad 2.125 \times 10^{-4}, \quad 3.15 \times 10^{-4}$ and $4.17 \times 10^{-4} \mathrm{~g} / \mathrm{mL}$ were not toxic but were potent enough to reduce significantly the toxic effects induced by ethinylestradiol in cultured human peripheral blood lymphocytes. The selected doses for the estimation of hsp70 expression in the third instar larvae of transgenic $D$. melanogaster (hsp70-lacZ) Bg9. i.e. 1, 2, 4 and $6 \mu \mathrm{l} / \mathrm{mL}$ were not toxic though reduced significantly the expression of $h s p 70$ induced by 0.5 and1.0 $\mu \mathrm{l} / \mathrm{mL}$ of ethinylestradiol.
\end{abstract}

\section{Introduction}

Estrogens are used not only for the cure of many types of sexual disorders but also in oral contraceptive formulations. ${ }^{1}$ There is sufficient evidence of estrogen carcinogenicity and genotoxicity in various experimental models. ${ }^{2-}$ 3 The prolonged use of steroids has been reported to induce various types of cancer. ${ }^{4}$ All living organisms under stressful conditions respond by synthesizing heat shock proteins (HSPs). ${ }^{5-6}$ In recent years, $h s p 70$ has been con- sidered to be one of the candidate genes for predicting the cytotoxicity against environmental chemicals. ${ }^{7-9}$ Plumbago zeylanica is commonly known as white lead wort and is found abundantly in the plains of Bengal and Southern India. ${ }^{10}$ In India, it has been used traditionally, against a number of ailments such as skin diseases, diarrhea, and leprosy.11 Its crude extract has been reported to have antimicrobial, antimutagenic and antitumor properties. ${ }^{12}$ The studies related to the antimutagenic effects of its extract are limited. The modulatory effects of some plant extracts have been studied using Drosophila melanogaster as a model. ${ }^{13-15}$ The fruit fly $D$. melanogaster is a well established model for the study of antigenotoxic effects of different compounds and mixtures due to its well documented genetics and developmental biology. ${ }^{16} D$. melanogaster is also capable of activating promutagens and procarcinogens. ${ }^{17}$

In our earlier study the effect of ethinylestradiol was studied for the hsp70 expression at $0.25,0.50,1.0$ and $2.0 \mu \mathrm{l} / \mathrm{ml}$ in the third instar larvae of transgenic $D$. melanogaster (hsp70-lacZ) Bg 9 and was found to increase the $h s p 70$ expression significantly, as compared to the untreated at 0.50, 1.0 and $2.0 \mu \mathrm{l} / \mathrm{mL}$. $^{18}$ In the present study we have evaluated the effects of leaf extract of $P$. zeylanica on ethinylestradiol induced hsp70 expression in the third instar larvae of transgenic $D$. melanogaster (hsp70-lacZ)Bg ${ }^{9}$ in order to verify the model to be used for antigenotoxicity studies. The effect of $P$. zeylanica extract was also studied against the genotoxicity of ethinylestradiol in the presence of metabolic activation (S9mix) in cultured human peripheral blood lymphocytes.

\section{Materials and Methods}

\section{Chemicals}

Ethinylestradiol (Sigma); RPMI 1640, Fetal calf serum, Phytohaemagglutinin-M, antibiotic-antimycotic mixture (In Vitrogen); Dimethylsulphoxide, 5-Bromo-2-deoxyuridine, Colchicine (SRL, India); Giemsa stain (Merck), S9 mix from rat liver Sprague-Dawley (Sigma); 0-nitrophenyl- $\beta$-D-galactopyranoside, sodium carbonate, maize powder (Himedia).

\section{Extract preparation}

$P$. zeylanica leaves were collected from the nursery of Forest Research Institute (FRI), Dehradun (UK) and were air dried and grounded to fine powder. Extraction was performed by soaking samples (30 gm of dry weight) in $300 \mathrm{ml}$ of acetone for $8-10 \mathrm{~h}$ at $40^{\circ} \mathrm{C}-60^{\circ} \mathrm{C}$ in Soxhlet's apparatus. After filtra-
Correspondence: Yasir Hasan Siddique, Section of Genetics, Department of Zoology, Aligarh Muslim University, Aligarh-202002 (U.P.), India. E-mail: yasir_hasansiddique@rediff.com

Key words: Plumbago zeylanica, ethinylestradiol, Drosophila melanogaster, blood lymphocytes.

Acknowledgements: the authors are grateful to the Chairman, Department of Zoology, Aligarh Muslim University, Aligarh for providing laboratory facilities. We are also thankful to Dr. D. Kar Chowdhuri, Scientist F \& Head Embryotoxicology, IITR, Lucknow, UP, India for providing $\mathrm{Bg}^{9}$ Drosophila strain.

Received for publication: 24 June 2011. Revision received: 22 July 2011.

Accepted for publication: 23 July 2011.

This work is licensed under a Creative Commons Attribution NonCommercial 3.0 License (CC BYNC 3.0).

(C) Copyright Y.H. Siddique et al., 2011

Licensee PAGEPress, Italy

Alternative Medicine Studies 2011; 1:e7

doi:10.4081/ams.2011.e7

tion, the excess of solvent was removed by rotatory evaporator. The extract concentrations of $1.075 \times 10^{-4}, 2.127 \times 10^{-4}, 3.14 \times 10^{-4}$ and $4.17 \times 10^{-4} \mathrm{~g} / \mathrm{mL}$ in culture medium were established. 14

\section{Human lymphocyte culture}

Heparinized blood samples were collected from 5 healthy donors ( 2 males, 3 females, non smokers, age range 22-28). Whole blood $(0.5 \mathrm{~mL})$ was added to $5 \mathrm{ml}$ of culture medium (pH 6.8-7.0), supplemented with $10 \%$ fetal calf serum, 10\% antibiotic-antimycotic mixture and $1 \%$ phytohaemagglutinin of the final volume of the cell culture. ${ }^{19}$ The culture tubes were then placed in the incubator at $37^{\circ} \mathrm{C}$ for $24 \mathrm{hr}$.

\section{Chromosomal aberration analysis}

Following $24 \mathrm{hr}$ incubation, the treatment of $10 \mu \mathrm{M}$ of ethinylestradiol (dissolved in DMSO, 5 $\mu \mathrm{l} / \mathrm{mL}$ ) was given along with $0.5 \mathrm{ml}$ of $S 9$ mix. A separate treatment of $10 \mu \mathrm{M}$ of ethinylestradiol (dissolved in DMSO, $5 \mu \mathrm{l} / \mathrm{mL}$ ) was also given along with $1.075 \times 10^{-4}, 2.127 \times 10^{-4}, 3.15 \times 10^{-4}$ and $4.17 \times 10^{-4} \mathrm{~g} / \mathrm{mL}$ of $P$. zeylanica extract along with $0.5 \mathrm{~mL}$ of $\mathrm{S} 9 \mathrm{mix}$. The cells were incubated with $\mathrm{S} 9 \mathrm{mix}$ for $6 \mathrm{hr}$. The cells were then collected by centrifugation and washed in the prewarmed medium to remove the excess traces of S9 mix and added drugs and were further incubated for the remaining $42 \mathrm{hr}$. The negative (DMSO, $5 \mu \mathrm{l} / \mathrm{mL}$ ) and positive (cyclophosphamide, $0.16 \mu \mathrm{g} / \mathrm{mL}$ ) controls were also run simultaneously. Treatment of $0.2 \mathrm{ml}$ of 
colchicine $(0.2 \mu \mathrm{g} / \mathrm{mL})$ was given to the culture tubes prior to $1 \mathrm{hr}$ of cell harvesting. Cells were then centrifuged at $1000 \mathrm{rpm}$ for $10 \mathrm{~min}$. The supernatant was removed and $8 \mathrm{ml}$ of prewarmed $\left(37^{\circ} \mathrm{C}\right) 0.075 \mathrm{M} \mathrm{KCl}$ (hypotonic solution) was added and the cells were resuspended and incubated at $37^{\circ} \mathrm{C}$ for $15 \mathrm{~min}$. The supernatant was removed after centrifugation at 1000 rpm for $10 \mathrm{~min}$, and subsequently $5 \mathrm{~mL}$ of chilled fixative was added. The fixative was removed by centrifugation and the procedure was repeated twice. To prepare slides, 3 to 5 drops of the fixed cell suspension were dropped on a clean slide and air dried. The slides were then stained in a Giemsa solution in phosphate buffer (pH 6.8) for 15 min. The slides were coded before scoring and 50 metaphases were scored for chromosomal aberrations (TCAs) per dose per treatment per donor according to the recommendations of EHC 51 for short term tests for mutagenic and carcinogenic chemicals. ${ }^{20}$

\section{Soluble O-nitrophenyl- $\beta$-D-galac- topyranoside (ONPG) assay}

A transgenic $D$. melanogaster line that expresses a bacterial- $\beta$-galactosidase as a response to stress was used in the present study. ${ }^{21}$ In the said strain of fly, the transformation vector is inserted with a P-element, the line contains wild type $h s p 70$ sequence up to the lacZ fusion point. The flies and larvae were cultured on standard Drosophila food containing agar, cornmeal, sugar and yeast at $24^{\circ} \mathrm{C} .22$ Ethinylestradiol was dissolved in dimethylsulphoxide and 0.50 and $1.0 \mu \mathrm{l} / \mathrm{mL}$ of food concentrations were established. $0.50 \mu \mathrm{l} / \mathrm{mL}$ of ethinylestradiol was mixed separately with 1 , 2,4 and $6 \mu \mathrm{l} / \mathrm{mL}$ of $P$. zeylanica extract in food. The similar food concentrations were established with $1 \mu \mathrm{l} / \mathrm{mL}$ of ethinylestradiol. The third instar larvae were allowed to feed on them for different time intervals $(6,24$ and 48 $\mathrm{hr}$ ). We followed the method as described by Nazir et al. ${ }^{22}$ Briefly, after washing in phosphate buffer the larvae were taken in a microcentrifuge tube (20 larvae/tube, 5 replicates /group), permeabilized for $10 \mathrm{~min}$ in acetone, and incubated overnight at $37^{\circ} \mathrm{C}$ in $600 \mu \mathrm{L}$ of ONPG staining buffer. Following incubation, the reaction was stopped by adding $300 \mu \mathrm{L}$ of $\mathrm{Na}_{2} \mathrm{CO}_{3}$. The extent of reaction was quantified by measuring the absorbance at $420 \mathrm{~nm}$ using systronics UV/VIS spectrophotometer 118, India. Dimethylsulphoxide at the dose of 2 $\mu \mathrm{l} / \mathrm{ml}$ of food was used as a negative control and the third instar larvae were allowed to feed for different durations.

\section{Statistical analysis}

Statistical analysis was performed by one way analysis of variance (ANOVA) using the commercial Software Programme Stat Soft Inc (2007).

\section{Results}

The treatment of $10 \mu \mathrm{M}$ of ethinylestradiol in the presence of $\mathrm{S} 9$ mix results in a significant increase in TCA / Cell (Table 1). A significant decrease in the TCA cell was observed when the treatment of $10 \mu \mathrm{M}$ of ethinylestradiol was given along with $1.075 \times 10^{-4}$, $2.127 \times 10^{-4}, 3.14 \times 10^{-4}$ and $4.17 \times 10^{-4} \mathrm{~g} / \mathrm{mL}$ of $P$. zeylanica extract (Table 1). The treatment of $10 \mu \mathrm{M}$ of ethinylestradiol in the presence of S9 mix was associated with $0.16 \pm 0.153 \mathrm{TCA} / \mathrm{Cell}$. The treatment of $1.075 \times 10-4,2.125 \times 10-4$, $3.15 \times 10^{-4}$ and $4.17 \times 10^{-4} \mathrm{~g} / \mathrm{mL}$ of plant extract along with the $10 \mu \mathrm{M}$ of ethinylestradiol in the presence of $\mathrm{S} 9 \mathrm{mix}$ was associated with $0.075 \pm 0.091,0.056 \pm 0.084,0.044 \pm 0.073$ and $0.032 \pm 0.041 \mathrm{TCA} /$ Cell, respectively (Table 1). The exposure of the third instar larvae to 0.50 $\mu \mathrm{l} / \mathrm{mL}$ of ethinylestradiol for 6,24 and $48 \mathrm{hr}$ was associated with the mean absorbance values of $0.2802 \pm 0.0070,0.2931 \pm 0.0083$ and $0.3146 \pm 0.0077$, respectively. The exposure of the third instar larvae of transgenic $D$. melanogaster (hsp70-lacZ) Bg ${ }^{9}$ to $0.50 \mu \mathrm{L} / \mathrm{mL}$ of ethinylestradiol along with different concentrations of plant extract i.e. 1, 2, 4 and $6 \mu \mathrm{l} / \mathrm{ml}$ for $6 \mathrm{hr}$ were found to be associated with mean absorbance values of $0.2511 \pm 0.0069$, $0.2433 \pm 0.0053,0.2401 \pm 0.0044$ and $0.2346 \pm$ 0.0041 , respectively (Table 2 ). The exposure of the third instar larvae of transgenic $D$. melanogaster(hsp70-lacZ)Bg ${ }^{9}$ to $0.50 \mu \mathrm{l} / \mathrm{mL}$ of ethinylestradiol along with different concentrations of plant extract i.e. 1, 2, 4 and 6 $\mu \mathrm{l} / \mathrm{mLfor} 24 \mathrm{hr}$ were associated with the mean absorbance values of $0.2703 \pm 0.0072,0.2614 \pm$
$0.073,0.2533 \pm 0.0052$ and $0.2421 \pm 0.0046$ respectively (Table 2). The exposure of the third instar larvae of transgenic $D$. melanogaster (hsp70-lacZ) Bg 9 to $0.50 \mu \mathrm{l} / \mathrm{mL}$ of ethinylestradiol along with different concentrations of plant extract i.e. $1,2,4$ and $6 \mu \mathrm{l} / \mathrm{ml}$ for $48 \mathrm{hr}$ were associated with the mean absorbance values of $0.2915 \pm 0.0081,0.2833 \pm$ $0.0073,0.2767 \pm 0.0070$ and $0.2704 \pm 0.0063$, respectively (Table 2). The exposure of the third instar larvae to $1.0 \mu \mathrm{l} / \mathrm{mL}$ of ethinylestradiol for 6, 24 and $48 \mathrm{hr}$ was associated with the mean absorbance value of $0.1303 \pm 0.0073$, $0.3094 \pm 0.0089$ and $0.3277 \pm 0.0086$, respectively (Table 2). The exposure of the third instar larvae of transgenic D. melanogaster (hsp70lacZ)Bg9 for $6 \mathrm{hr}$ to $1.0 \mu \mathrm{l} / \mathrm{mL}$ of ethinylestradiol along with the different concentrations of plant extract i.e.1, 2, 4 and $6 \mu \mathrm{l} / \mathrm{mL}$ were associated with the mean absorbance values of $0.2947 \pm 0.0089,0.2721 \pm 0.0084,0.2634 \pm 0.0079$ and $0.2441 \pm 0.0066$, respectively (Table 2 ). The exposure of the third instar larvae of transgenic D. melanogaster (hsp70-lacZ)Bg9 for 24 hr to $1.0 \mu \mathrm{l} / \mathrm{mL}$ of ethinylestradiol along with the different concentrations of plant extract i.e. $1,2,4$ and $6 \mu \mathrm{l} / \mathrm{mL}$ were associated with the mean absorbance values of $0.2843 \pm 0.0059$, $0.2711 \pm 0.0063,0.2653 \pm 0.0071$ and $0.2601 \pm$ 0.0064 , respectively (Table 2 ). The exposure of the third instar larvae of transgenic $D$. melanogaster (hsp70-lacZ)Bg ${ }^{9}$ for $48 \mathrm{hr}$ to 1.0 $\mu \mathrm{l} / \mathrm{ml}$ of ethinylestradiol along with the different concentrations of plant extract i.e.1, 2, 4 and $6 \mu \mathrm{l} / \mathrm{ml}$ were associated with the mean absorbance values of $0.2997 \pm 0.0053$, $0.2819 \pm 0.0072,0.2784 \pm 0.0073$ and $0.2723 \pm$ 0.0068 , respectively (Table 2 ).

Table 1. Effect of Plumbago zeylanica extract on chromosomal aberrations induced by ethinylestradiol in cultured human lymphocytes.

$\begin{array}{llllll}\text { Theatments } & \text { Chromosomal aberrations } & & \text { TCA/Cell } \pm \text { SE } \\ \text { CB } & \text { ICB CG ICG CA ICA CE P DS }\end{array}$

$\mathrm{EE}(\mathrm{M})$

\begin{tabular}{lcccccccccc}
10 & 14 & 9 & 5 & 3 & 3 & 2 & 1 & 2 & 1 & $0.16 \pm 0.153^{\mathrm{a}}$ \\
$\mathrm{EE}(\mathrm{M})+\mathrm{PZE}(\mathrm{g} / \mathrm{mL})$ & & & & & & & & & & \\
$10+1.075 \times{ }^{10-4}$ & 9 & 4 & 3 & 2 & 1 & 0 & 0 & 0 & 0 & $0.076 \pm 0.09 \mathrm{~b}^{\mathrm{b}}$ \\
$10+2.25 \times 10-4$ & 7 & 3 & 2 & 1 & 1 & 0 & 0 & 0 & 0 & $0.056 \pm 0.084^{\mathrm{b}}$ \\
$10+3.15 \times 10-4$ & 5 & 3 & 2 & 1 & 0 & 0 & 0 & 0 & 0 & $0.044 \pm 0.073^{\mathrm{b}}$ \\
$10+4.17 \times 10-4$ & 3 & 2 & 2 & 1 & 0 & 0 & 0 & 0 & 0 & $0.032 \pm 0.041^{\mathrm{b}}$ \\
$\mathrm{PZE}(\mathrm{g} / \mathrm{mL})$ & & & & & & & & & & \\
$1.075 \times 10-4$ & 5 & 0 & 2 & 1 & 0 & 0 & 0 & 0 & 0 & $0.032 \pm 0.049$ \\
$2.125 \times 10-4$ & 6 & 0 & 1 & 1 & 0 & 0 & 0 & 0 & 0 & $0.032 \pm 0.043$ \\
$3.15 \times 10-4$ & 5 & 0 & 1 & 1 & 0 & 0 & 0 & 0 & 0 & $0.028 \pm 0.031$ \\
$4.17 \times 10-4$ & 4 & 1 & 1 & 1 & 0 & 0 & 0 & 0 & 0 & $0.028 \pm 0.034$ \\
Untreated & 3 & 1 & 1 & 0 & 0 & 0 & 0 & 0 & 0 & $0.02 \pm 0.023$ \\
Negative control & & & & & & & & & & \\
\hline (DMSO 5 l/mL) & 4 & 2 & 1 & 2 & 1 & 0 & 0 & 0 & 0 & $0.04 \pm 0.021$ \\
Positive control & & & & & & & & & &
\end{tabular}

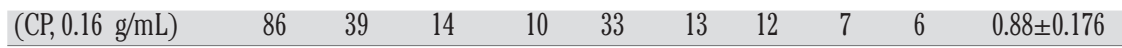

A total 250 cells were scored for chromosomal aberrations. aP $<0.005$ significantly different from the untreated. $\mathrm{bP}<0.005$ significantly different from the EE; CB, chromatid break; ICB, isochromatid break; CG, chromatid gap; ICG, isochromatid gap; CA, chromosome accentric fragment; ICA, isochromatid accentric fragment; CE, chromatid exchange; P, pulverization; DS, dicentric chromosome; EE, ethinylestradiol; PZE, Plumbago zeylanica extract. 


\section{Discussion}

The results of the present study reveal that the leaf extract of $P$. zeylanica is potent in reducing the genotoxic as well as cytotoxic effects induced by ethinylestradiol. Our earlier study showed that ethinylestradiol at $0.50,1.0$ and $2.0 \mu \mathrm{l} / \mathrm{mL}$ of food concentration induced significant expression of $h s p 70.18$ The selected doses of $P$. zeylanica are not genotoxic itself, but reduce the genotoxic effects of $10 \mu \mathrm{M}$ of ethinylestradiol. The results also show that the selected doses of $P$. zeylanica extract are not potent in inducing the significant expression of $h s p 70$ but are potent enough to reduce the hsp70 expression induced by 0.50 and $1.0 \mu \mathrm{l} / \mathrm{ml}$ of ethinylestradiol. Having distinct protective role in living systems, HSPs are being exploited by toxicologists. ${ }^{23-24}$ Being effective biosensor to even a minor assault, $h s p 70$ expression is considered now-a-days to be an effective marker for toxicological evaluations.25 Drosophila is a well established animal model for geneticists and molecular biologists. In the past years a significant contribution has been made by successfully employing transgenic $D$. melanogaster as an alternative animal model for toxicological research. ${ }^{26}$ Though there is no comparative data, the studies by Hirsch et al. 27 indicates that fly and human have similar dose response relationship with lead exposure. Our earlier study with ethinylestradiol has shown that the metabolic activation and possible conversion of it to a reactive species is responsible for the genotoxicity.3 HSPs are formed in response to stressors like lipid peroxidation assay, DNA damage, osmotic imbalance, protein misfolding, membrane perturbation, metal and heat shock etc. ${ }^{8} \mathrm{~A}$ dose dependent decrease in the activity of $\beta$-galactosidase clearly demonstrates the protective effect of the plant extract. Medicinal plants and their products have been used for centuries for cure of various ailments. 28 The main component of the $P$. zeylanica extract i.e. Plumbagin at 4,8 , and $16 \mathrm{mg} / \mathrm{kg}$.bw has already been reported to induce micronuclei in the bone marrow of Swiss albino mice.10 Again the root extract of $P$. zeylanica at 250 and $500 \mathrm{mg} / \mathrm{kg}$.bw given orally for 5 days reduced significantly micronucleated polychromatic erythrocytes.10 The verification of the possible mutagenic and antimutagenic effects of medicinal plants, infusion / extract is an important factor in these studies. Some plants may possess substances that can modulate the genotoxicity of the other compounds.29 The leaf extracts and various natural plant products have been reported to reduce the genotoxic effects of synthetic steroids.30-33 An increase in the frequency of chromosomal aberrations in the peripheral blood lymphocytes is associated with an overall increase in the risk of having

Table 2. $\beta$-galactosidase activity measured in transgenic Drosophila melanogaster (bsp70lac $Z) B g^{9}$ third instar larvae exposed to different concentrations of ethinylestradiol and Plumbago zeylanica extract.

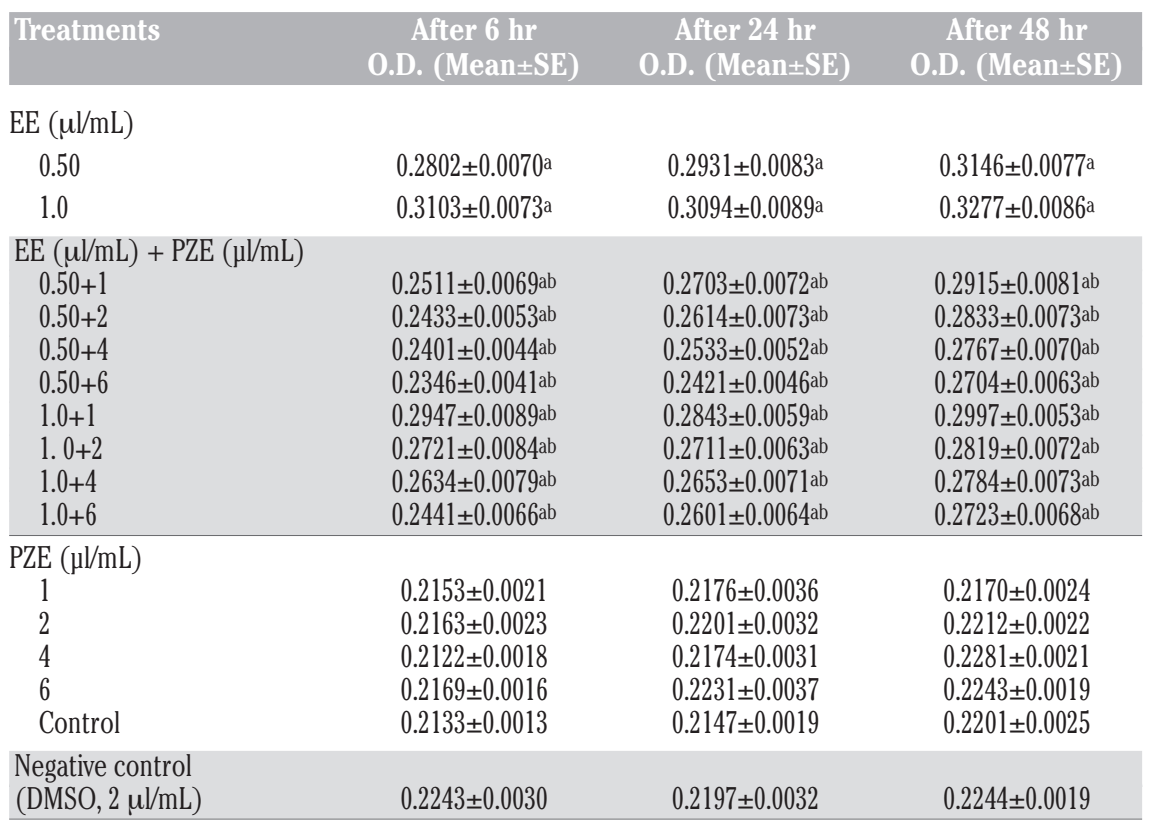

aSignificant at $\mathrm{P}<0.001$ with respect to control. bSignificant at $\mathrm{P}<0.001$ with respect to Ethinylestradiol treatment

cancer and the reduction in the genotoxic effects by certain natural plant agents/ extracts may be helpful in reducing the possibility of having cancer at higher doses or by prolonged therapy of steroids. 31,34 The protective effect of $P$. zeylanica in causing significant reduction in chromosomal aberrations and reduction in the activity of $h s p 70$ in the present study is due to the direct action of these compounds present in the extract of $P$. zeylanica against ethinylestradiol by inactivating it enzymatically or chemically. The present study also supports the use of transgenic $D$. melanogaster ( $h s p 70-l a c Z$ ) Bg ${ }^{9}$ model for the antigenotoxicity studies. The compounds present in the extract may act synergistically, as compared to a compound in isolation and this supports the indigenous system of medicine namely Ayurvedic, Siddha and Unani, that have been in existence for several centuries. 35 The identification and characterization of the compounds present in the $P$. zeylanica extract and to determine their particular functions will be the part of our future study.

\section{References}

1. Schwend TH, Lippman JS. Comparative review of recently introduced oral contraceptives containing norgestinate, desogestrel, and gestodene and older oral contraceptives, IN, E.J. Pavlik (Ed.), Estrogen, Progestins and their antagonists, Birkhauser, Boston, 1996; pp. 273-296.
2. Joosten HF, van Acker FF, van den Dobbelsteen DJ, et al. Genotoxicity of hormonal steroids. Toxicol Lett 2004;151:1134.

3. Siddique YH, Beg T, Afzal M. Antigenotoxic effects of ascorbic acid against megestrol acetate induced genotoxicity in mice. Hum Exp Toxicol 2005;24:121-7.

4. IARC. International Agency for Research on Cancer, Oral Contraceptives, Combined (Group 1), 1999; Vol. 72: pp. 49.

5. Nover L. The heat shock response. Boca Raton, FL: CRC Press 1991;5:344.

6. Nover L. Heat shock response of eukaryotic cells. Berlin: Springer-Verlag. 1994.

7. Bierkens JGEA. Applications and pitfalls of stress proteins in bio-monitoring. Toxicology 2000;153:61-72.

8. Mukhopadhyay I, Saxena DK, Chowdhuri DK. Hazardous effects of effluent from the chrome plating industry: $70 \mathrm{kDa}$ heat shock protein expression as a marker of cellular damage in transgenic Drosophila melanogaster (hsp70-lacz)Bg9. Environ Health Persp 2003;3:1926-32.

9. Mukhopadhyay I, Nazir A, Mahmood K, et al. Toxicity of argemone oil: Effect on hsp70 expression and tissue damage in transgenic Drosophila melanogaster (hsp70-lacz)Bg9. Cell Biol Toxicol 2002;18: $1-11$.

10. Sivakumar V, Devaraj SN. Protective effect of Plumbago zeylanica against cyclophosphamide induced genotoxicity and oxidative stress in Swiss albino mice. Drug Chem Toxicol 2006;29:279-88. 
11. Chopra RN, Nayer SL, Chopra IC. Glossary of Indian Medicinal Plants, 3rd (Ed.), New Delhi, CSIR, India, 1992; pp. 7-246.

12. Beg A Z, Ahmad I. Effect of Plumbago zeylanica extract and certain agents on multi drug resistant bacteria of clinical origin. World J Microbiol Biotechnol 2000;16:8414.

13. de Sousa NC, de Rezende AAA, da Silva RMG, et al. Modulatory effects of Tabebuia impetiginosa (Lamiales, Bignoniaceae) on doxorubicin induced somatic mutation and recombination in Drosophila melanogaster. Genet Mol Biol 2009;32:3828.

14. Castro AJS, Grisolia CK, de Araujo BC, et al. Recombinogenic effects of the aqueous extract of pulp from pequi fruit (Caryocar brasiliense) on somatic cells of Drosophila melanogaster. Genet Mol Res 2008;7:137583.

15. Ahmed ES, Twaty NH, Fakiha KG, et al. Mutagenic and antimutagenic effects of some plant extracts in Drosophila melanogaster. Nature Sci 2010;8:77-82.

16. Dalouh A, Amkiss S, Skail SN, et al. Genotoxicity and antigenotoxicity studies of commercial Argania spinosa seed oil (argan oil) using the wing somatic mutation and recombination test in Drosophila melanogaster. African J Food Sci 2010;4: 434-9.

17. Serikaya R, Cakir S. Genotoxicity testing of four food preservatives and their combination in the Drosophila wing spot test. Environ Tox Pharm 2005;20:424-30.

18. Siddique YH, Ara G, Afzal M. Effect of ethinylestradiol on hsp70 expression in transgenic Drosophila melanogaster (hsp70-lacz)Bg9. Pharmacology online 2011;1:398-405.

19. Carballo MA, Alvarez S, Boveris S. Cellular stress by light and Rose Bengal in human lymphocytes. Mutat Res 1993;288:215-22.

20. IPCS. International Programme on Chemical Safety: Environmental Health Criteria 49, Guidelines for the study of genetic effects in human populations, WHO, Geneva 1985; pp. 25-54.

21. Lis JT, Simon JA, Sutton CA. New heat shock puffs and $\beta$-galactosidase activity resulting from transformation of Drosophila with an hsp70-lacz hybrid gene. Cell 1983;35:403-13.

22. Nazir A, Mukhopadhyay I, Saxena DK, et al. Evaluation of toxic potential of captain: induction of hsp70 and tissue damage in transgenic Drosophila melanogaster (hsp70-lacz)Bg9. J Biochem Mol Toxicol 2003;17:98-107.

23. Chowdhuri DK, Nazir A, Saxena DK. Effect of three chlorinated pesticides on hsr w stress gene in transgenic Drosophila melanogaster. J Biochem Mol Toxicol 2001;15:173-86.

24. Chowdhuri DK, Saxena DK, Vishwanathan PN. Effect of hexachlorohexane (HCH), its isomers, and metabolites on hsp70 expression in transgenic Drosophila melanogaster. Pesticide Biochem Physiol 1996;63:15-25.

25. Guven K, Duce JA, de Pomerai DI. Evaluation of a stress inducible transgenic nematode strain for rapid aquatic toxicity testing. Aquatic Toxicol 1994;29:19-137.

26. Benford DJ, Hanley AB, Bottrill K, et al. Biomarkers as predictive tools in toxicity testing. The report and recommendatioins of ECVAM Workshop 40 ATLA 2000;28:11931.

27. Hirsch HV, Mercer J, Sambaziotis H, et al. Behavioural effects of chronic exposure to low levels of lead in Drosophila melanogaster. Neurotoxicology 2003;24: 435-42.

28. Asolkar AV, Kakkar KK, Charke OJ.
Glossary of Indian Medicinal Plants with active principles. CSIR, New Delhi 1992;1:187.

29. Roncada T, Vicentini VFP, Mantovani MS. Possible modulating actions of plants extracts, on the chromosome breaking activity of MMC and Ara C in human lymphocytes in vitro. Toxicol in vitro 2004;16:617-22.

30. Siddique YH, Ara G, Beg T, et al. Antigenotoxic effect of nordihydroguaiaretic (NDGA) against chlormadinone acetate induced genotoxic damage in mice bone marrow cells. J Nat Med 2008;62:526.

31. Siddique YH, Ara G, Beg T, et al. Antigenotoxic role of Centella asiatica $\mathrm{L}$. extract against cyproterone acetate induced genotoxic damage in cultured human lymphocytes. Toxicol in vitro 2008;22:10-7.

32. Siddique YH, Beg T, Afzal M. Protective effect of nordihydroguaiaretic acid (NDGA) against norgestrel induced genotoxic damage. Toxicol in vitro 2006;20:22733.

33. Siddique YH, Afzal M. Protective role of allicin and L-ascorbic acid against the genotoxic damage induced by chlormadinone acetate in cultured human lymphocytes. Indian J Exp Biol 2005;43:769-72.

34. Hagmar L, Bonnassi S, Stronberg U, et al. Chromosomal aberrations in human lymphocytes predict human cancer: A report from the European Study Group on cytogenetic biomarkers and health (BSCH). Canc Res 1998;58:4113-21.

35. Chitravadivu C, Manian S, Kalaichelvi K. Quantitative analysis of selected medicinal plants, Tamil Nadu, India. Middle East J Sci Res 2009;4:144-6. 